\title{
Peculiarities of education in optics for masters of physical faculties of universities
}

\section{Leonid Poperenko}

Leonid V. Poperenko, "Peculiarities of education in optics for masters of physical faculties of universities," Proc. SPIE 4588, Seventh International Conference on Education and Training in Optics and Photonics, (28 May 2002); doi: 10.1117/12.468731

SPIE Event: Education and Training in Optics and Photonics 2001, 2001, Singapore, Singapore 


\title{
Peculiarities of education in optics for Masters of Physical Faculties of Universities
}

\author{
Poperenko Leonid Volodymyrovich
}

Taras Shevchenko Kyiv National University, 64, Volodymyrska Str., Kyiv 01033, Ukraine, e-mail: plv@phys.univ.kiev.ua

\begin{abstract}
The comparison of basic educational approaches in optics studying is carried out. It is shown that considered models supplement each other. The advantages and lacks of educational models are exhibited. It is shown that the educational level of the students which study according to the proposed system is not worse than others. The basic problems of education at physical faculty of Taras Shevchenko Kyiv National University, in particular on Optics Division are reviewed. The perspectives for the development of education in optics in Ukrainian universities are discussed.
\end{abstract}

Keywords: education, optics, physical faculties, university.

\section{INTRODUCTION}

Only five countries left their traces in the world system of higher education, although the organization forms of educational process are unique in each university. It is known that the majority of systems of higher education was developing with orientation on the five well-known historical models of universities namely Napoleon model (France), Humboldt model (Germany), American model (USA), British model and the Soviet model. Without detailed characteristic and comparison of listed models of universities one can affirm with confidence today, that standard of training of students on the physical faculty of Taras Shevchenko Kyiv National University is sufficiently high and it corresponds to the highest world standards. There are many examples confirming this fact. Many our 
graduates are working in the research institutes of Western Europe countries successfully in spite of great competition for work places. One would think that reached standard of students training is high and it is necessary to keep it only. But the experience of work during the last ten years has shown that it is necessary to improve this standard even more. But it is very difficult, because now the prestige of the profession of physicist is rather loosed not only in Ukraine. In this paper the problem of the improvement of the education in optics within the programs of Ukrainian Universities is considered.

\section{DISCUSSION}

Now there are many reasons of the decrease of the attention of graduates from secondary schools to the natural sciences [1] namely economical, social and interdisciplinary ones. For example, about the last one: now anybody convincingly will not prove, that for the solution of fundamental problems, for instance, in area of nanotechnologies the physicists should play the first role, instead of chemists, or on the contrary, though the necessity of their tight cooperation for anybody does not cause doubts. And then, on the one hand, it is difficult (even the most authoritative professors) to determine an optimal list of the disciplines, the distribution of time for their learning, necessary and sufficient scope of the material for a adoption by the student of physical faculty instead of chemical one or on the contrary. Thus, it is necessary to find a principal difference between these two specialties, because the entrant should have a reliable landmarks to decide what faculty (even from these two) he wants enter. An economic aspect must be taken into account here too. It is without doubts: the customers of specialists have less and less money (at least in Ukraine), and at the same time the future executives have more and more desire not only to predict the market condition in area of science and high technologies and productions, to receive soon interesting creative work, but also to determine that optimal quantity of subjects (courses), which are necessary for their deep training. So the responsibility of two the interested parts in the educational process increases too. The enhanced demand for obtaining of deep knowledge on actual courses from below and the 
proposal from above on the effective technique of study for their qualitative adoption by student. In this connection both before university and before the student there is a selection: a broad profile of studying in a direction of understanding a lot of general and special courses at the sufficient level, or strict specialization with the detailed learning of more restricted area of the related disciplines. For the decision of such problem in the education and training in Optics we have used:

- optimal set of special optical courses and distribution of the time for they study by students of just physics department (but not physical profile);

- determination of optimal numbers of courses, that should be studied as deeply as it possible and performance of practical tasks and presentation of appropriate reports;

- proposition of effective methods for qualitative study of the selected courses.

To decide the dilemma "education" on wide spectrum of general and special subjects (1) - restrictive specialization with profound study of limited number of similar disciplines (2)" our teaching practice in Optics Division during 90-th years have shown, that the first approach was more preferable for 1-4 years students (bachelors), whereas the second one was effective for 5-6 years students (specialists, masters).

Taking into account modern needs and enjoying two approaches in the organization of educational process in Optics Division, the educational schedules, the list and the programs of the special courses on specialities "Laser and opto-electronic engineering" and "Solid state optics" are periodically renewed. Among many scientific schools of university at physical faculty two ones are necessary to emphasize [2]. The scientists of these schools are under the leadership of the correspondence members of the National Academy of Sciences of Ukraine Prof. L.A. Bulavin and Prof. V.A. Makara carry out the experimental and theoretical researches within the programs "The Condensed State of the matter" and "New materials and substances". The professors L.V. Poperenko and B.A. Okhrimenko are responsible for the developments of scientific subjects in the Optics Division. In Optics Division the majority of the students are engaged in scientific researches from the third course. Some of them have published 
the results of their investigations in the scientific journals and have reported their research achievements at international conferences. Owing to the joint efforts of young scientists of Optics Division and executive leaders of Ukrainian Chapter of SPIE (The International Society for Optical Engineering) at physical faculty of Taras Shevchenko Kyiv National University the Student Chapter of SPIE was organized in 2001. Besides the Second International Young Scientists Conference "Problems of Optics and high technology material science", Kyiv, Ukraine, October 25-26, 2001 was held. In this connection the studying process in Optics Division took supplementary impulse.

\section{CONCLUSIONS}

In the whole the contribution to the optical education of the scientists of physical faculty is rather valuable and noticeable not only in Ukraine but abroad too. Today Physical faculty as well as Optics Division is the most important center for organization of educational scientific, research process for the students and post-graduate students among faculties of natural sciences of Taras Shevchenko Kyiv National University.

\section{REFERENCES}

1. I. P. Pinkevych, L. V. Poperenko, Practice of experimental preparation at physical faculty of the schoolboys for International Olympiads of young physicists. Abs. of 2-nd Inter. Young Sci. Conf. "Scientific Problems of Optics and High Technology Material Science", Kyiv, 2001, P. 9.

2. L. A. Bulavin, L.V. Poperenko, Pecularities of education in physical faculties of universities. Abstr. of 2-nd Inter. Young Sci. Conf. "Scientific Problems of Optics and High Technology Material Science", Kyiv, 2001, P. 7. 